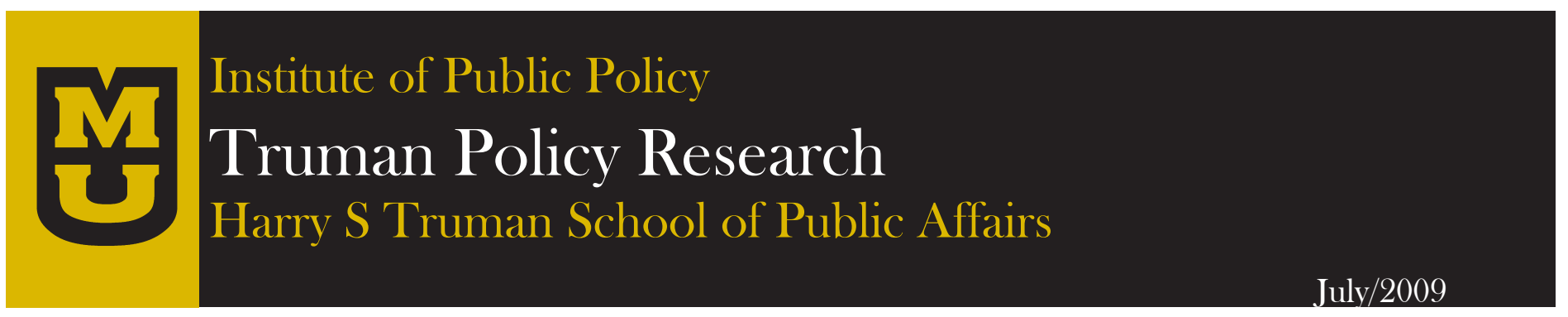

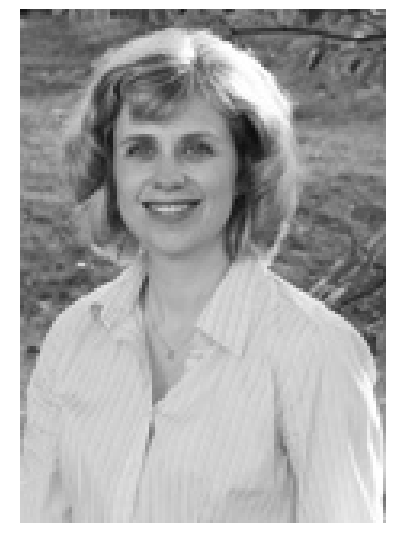

Dr. Lael Keiser is an Associate Professor at the Harry S Truman School of Public Affairs and the Department of Political Science at the University of Missouri.

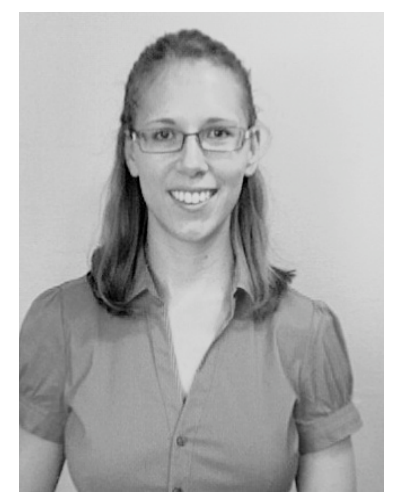

Susan Miller is a doctoral candidatein the Department of Political Science at the University of Missouri.

\title{
The Impact of Organized Interests on Eligibility Determination: The Case of Veterans' Disability Compensation
}

\section{Lael Keiser and Susan Miller}

\section{Introduction}

A bureaucracy has a profound impact on public policy when it determines eligibility for government programs. Organized interest groups can increase the amount of information the target population has about the program, help applicants with their applications, and work to inform policy makers when the process is not working well. By doing these things, interest groups can affect how government programs are implemented.

In this paper, we investigate the influence of veterans' interest groups on eligibility determinations in the Veterans' Disability Compensation (VDC) program across the fifty U.S. states to determine whether variations in veterans' organizations can explain why VA programs are implemented differently across the states. We find that the strength of veterans' groups affect demand for, access to, and effectiveness of the Veterans' Disability Compensation program. In states where veterans' groups have greater resources, more veterans file claims, more applications are approved, and, interestingly, the Veterans' Administration makes fewer errors in their eligibility decisions. We find no evidence, however, that the strength of veterans groups explain variation in the number of claims that are appealed, the percent of claims that are pending over 120 days, or the average disability rating given to successful claimants.

\section{Importance of the Issue}

Veteran's Disability Compensation is an important policy area to examine because the effectiveness of the VA's handling of VDC and the distribution of disability benefits has been questioned by the Inspector General of the Department of Veterans Affairs (2005) and the Government Accountability Office (GAO) (2005). In 2003, the GAO designated the compensation program as high-risk due to continuing problems with the timeliness and consistency of disability decisions (GAO 2005). The number of claims pending over six months increased by 61 percent from 2003 to 2005 (GAO 2005). Also, there is wide variation in the average disability compensation payment per veteran across the fifty states with the average payments varying from a low of $\$ 6,961$ in Illinois to a high of \$12,004 in New Mexico in 2004. These issues have also received the attention of the media and elected officials (see for example, Adams 2007).

\section{Interest Groups and Eligibility Determination}

We look at veterans' groups to assess whether variation in the resources of these organizations can explain state differences in eligibility determination. Interest groups and agencies have a reciprocal relationship. Interest groups are a resource for the bureaucracy and help bureaucrats raise public awareness of important issues and persuade public opinion (Hrebenar 1997).

This brief was edited by James Harrington. It is based on an article in the Journal of Public Administration Research and Theory (forthcoming). 
The support of interest groups can help the bureaucracy gain autonomy and resources from political principals and help agencies secure budgets (Meier and Bohte 2007). Agencies also act as a resource for interest groups and these groups seek favorable outcomes for their clients at all stages in the policy process (Lowi 1969).

\section{Veterans' Disability Compensation Program}

Disability compensation is a monthly payment made by the VA to veterans with a physical or mental disability that was incurred in, or aggravated by, military service. Under this program, the VA attempts to compensate veterans for loss of earnings due to service-connected injuries (U.S. Veterans Affairs Office of Inspector General 2005). Compensation payments are based on a disability-rating schedule that rates disability in ten percent increments from 0 to 100 percent with the amount of compensation increasing as the veteran's level of disability increases. Eligibility for disability compensation requires that the veteran was discharged or released under conditions other than dishonorable and that his or her disease or injury was incurred or aggravated in the line of duty. Eligibility for disability compensation is not linked to income or unemployment status (U.S. Veterans Affairs Office of Inspector General 2005). In fiscal year 2004 , approximately 2.5 million veterans received disability compensation, which is 10.2 percent of the total U.S. veteran population, and the average annual disability compensation payment was $\$ 8,378$. The ten percent disability-rating category is the largest with 30.6 percent of beneficiaries receiving compensation at this level in 2004 and only 8.4 percent receiving 100 percent disability compensation (U.S. Veterans Affairs Office of Inspector General 2005).

Veterans' interest groups are especially active in the VDC program. Certain veterans' groups, such as the three groups included in this analysis - the American Legion, Disabled American Veterans (DAV), and Veterans of Foreign Wars of the United States (VFW), have a privileged relationship with the VA and play an important role in the eligibility claiming process by helping to attract clients, prepare claims, and represent claimants. In fact, many veterans' organizations have offices within state VA headquarters, which helps these groups serve their implementation role in the VDC program. For disability claiming purposes, certain veterans' groups, including the three used in this analysis, are permitted to sponsor veterans' service representatives who are recognized by the VA (U.S. Department of Veterans' Affairs 2007). The service representatives of the veterans' groups actively participate in service provision through their intake activities and their role as guides for applicants through the claiming process.
Despite being a federal program, VDC is administered in a decentralized fashion through VA regional offices in each state, one per state with three exceptions (CA has three offices and NY and PA have two). Regional offices are not "regional" in the traditional sense but state level offices; thus, we refer to them as state VA offices. The VDC claims for a particular state are processed at the state's VA office by VA claims examiners. The VA claims examiners develop, investigate, and authorize claims filed by veterans at the state's VA office and are the street-level bureaucrats who play a focal role in implementing VDC eligibility determination (U.S. Office of Personnel Management 1962).

Decisions about veterans' disability compensation are essentially state level decisions. In this paper, we explore the measures of service delivery by state to determine whether the strength of veterans' groups in a state have an impact on the implementation of the Veterans' Disability Compensation program.

\section{Measures of Impact}

We estimate the impact of veterans' groups in each state on three different dimensions of VDC program implementation (i.e., demand, access, and effectiveness.)

Demand represents the level of demand for VDC benefits (i.e., number of claims per state relative to the state's veteran population and number of denied claims that veterans appeal).

Access represents the accessibility of VDC benefits permitted by the state VA office (i.e., percent of awarded claims and the average disability rating for awarded claims).

Effectiveness represents the competence of the state VA office in implementing the VDC program. We focus on two types of effectiveness, how quickly the bureaucracy processes claims, e.g. the percent of claims that are pending for over 120 days; and how accurate the VA is in their determinations, e.g. the error rate. In the error rate, the VA does not separate errors on allowances and denials; therefore, our measure captures overall errors.

To measure the strength of veterans' groups, we use the percentage of veterans in each state who have joined one of the three principal veterans groups - the American Legion, the Disabled American Veterans, and the Veterans of Foreign Wars. These are the three largest congressionally chartered veterans' organizations in the U.S. (U.S. Department of Veterans Affairs 2007). 
We estimate the impact of the resources of veterans' groups on the implementation of VDC using Ordinary Least Squares Regression and take into account other factors that would affect policy implementation, such as attorney representation, the percent of veterans' living in the state who believe they have a disability, the size of the state population who are veterans and the average age of veterans living in the state. For a complete list of control variables and how we measure them, please see Keiser and Miller, forthcoming.

\section{Findings and Implications}

Demand for Government Benefits. Veterans' groups significantly influence the rate at which veterans claim disability compensation, though not the rate at which they appeal unfavorable decisions. One problem in many government programs is that those who meet the eligibility criteria do not seek assistance (Nelson 1980). While we cannot tell whether increasing claims leads to a greater percent of veterans getting the services they need, getting veterans to apply for benefits is an important part of service delivery. The positive effect on claim rates suggests that the influence of veterans' groups in generating demand for benefits lies in mobilizing potential claimants and that well mobilized groups may provide superior outreach programs. This difference in the impact of veterans' groups for claims and appeals may indicate that these groups focus more attention and energy on activating new claimants and focus less on mobilizing veterans who have already entered the system.

In order to gain an understanding of the magnitude of the impact of veterans' groups, we look at the impact of membership rates across the states by comparing claims rates in the lowest and highest membership states. The model predicts that if a state like Nevada that had the lowest level of mobilization (9.51 percent) increased its membership to be more like North Dakota that had the highest level of mobilization (67.7 percent), Nevada would increase the claiming rate by 22.8 percent. In Missouri, 22.7 percent of veterans are members of the three principal veterans' groups. If veterans in Missouri joined VA interest groups at the same rate of North Dakota, the model predicts that the claim rate would increase by 17.7 percent.

The findings also show that, in addition to the mobilization of veterans, the workload of individual claims examiners is inversely related to the claim rate, thought it does not impact the appeal rate. This finding suggests that as the number of VA claims examiners increases, they have more time to provide information to potential claimants and encourage claiming.

Access to Benefits. We find that the resources of veterans' groups significantly increases award rates, though not the average disability rating. The model predicts that shifting from the minimum membership rate in Nevada to the maximum in North Dakota would increases the award rate by 11 percent. If Missouri increased its membership rate to be more similar that of North Dakota, Missouri's award rate would increase by 8.5 percent.

Effective Implementation. While the strength of veterans' groups do not affect the percent of cases that are pending over 120 days, VA offices in states in which veterans' groups have greater resources make fewer errors than those in states in which veterans' groups have fewer resources. Moving from the minimum membership rate for veterans groups in Nevada (9.51 percent) to the maximum in North Dakota (67.7 percent) decreases error rate by 6.8 percent. If Missouri increased its veteran mobilization to be more similar to that of North Dakota, the model predicts the error rate would decrease by 5.3 percent. Because VDC error rates include errors of omission (i.e., wrongful denials), errors of commission (i.e., wrongful allowances), and inaccurate disability ratings, this finding suggests that these groups encourage the VA office to make better quality eligibility decisions either in general or perhaps by simply reducing wrongful denials. It suggests that strong, well-mobilized veterans' groups help VA offices secure greater resources from Washington, which lead to more effective VDC program implementation, and may also indicate that strong veterans' groups use their influence to pressure the state VA offices to perform well.

\section{Conclusion}

Our findings make a contribution to real world concerns about the VDC program. The implementation of the VDC program has been the focus of intense criticism for lack of consistency and poor performance in eligibility determinations. Scholars, stakeholders, and practitioners have questioned why certain aspects of eligibility determination vary across the U.S. fifty states. Our findings demonstrate that part of the explanation lies in variation in interest group strength across U.S. states. In so far as stakeholders seek to improve accuracy in VDC eligibility determination and expand demand and access, especially in states with lower award rates, our study suggests that advocates for veterans in the U.S. would be well served by efforts to mobilize potential members to join veterans' interest groups.

\section{References}

Adams, Chris. 2007. "Payments Vary Greatly for New

Veterans with Mental Illness.” Kansas City Star,

December 19, 2007, front page.

Hrebenar, R. 1997. Interest Group Politics in America. Armonk, NY: ME Sharpe.

Lowi, T. 1969. The End of Liberalism: Ideology, Policy, and the Crisis of Public Authority. New York: Norton.

Keiser, Lael R. and Susan M. Miller. N.D. "The Impact of 
Interest Groups on Eligibility Determination: the Case of

Veterans' Disability Compensation.” Journal of Public

Administration Research and Theory, forthcoming.

Meier, Kenneth. J., and John Bohte. 2007. Politics and the Bureaucracy: Policymaking in the 4th Branch of Government. 5th ed. Belmont, CA: Thompson/ Wadsworth.

Nelson, Barbara J. 1980. "Help-Seeking from Public Authorities: Who Arrives at the Agency Door?"

Policy Sciences 12: 175-192.

U.S. Government Accountability Office. 2005. "Claiming Processing Problems Persist and Major Performance Improvements may be Difficult." GAO-05-749.

U.S. Office of Personnel Management. 1962. "Position Classification Standard for Veteran Claims Examining Series, GS-0996." TS-40.

U.S. Veterans Affairs Office of Inspector General. 2005. "Review of Variances in VA Disability Compensation Payments." U.S. Department of Veterans Affairs.

Veterans of Foreign Wars of the United States. Veterans of Foreign Wars of the United States website. http://www. vfw.org/ (October 11, 2007).

\section{Suggested Citation}

Keiser, L., and Miller, S. (2009). "The Impact of Organized Interests on Eligibility Determination: The Case of Veterans' Disability Compensation" Report I22009. Retrieved [Month Day, Year], from University of Missouri Columbia, Institute of Public Policy

Web site: http://www.truman.missouri.edu/ipp/

Institute of Public Policy I37 Middlebush University of Missouri Columbia, Mo 652II http://www.truman.missouri.edu/ipp 